\title{
A Single Side Priority Based GA Approach for 3D Printing Center Integration to Spare Part Supply Chain in Automotive Industry
}

\author{
Umut Rıfat TUZKAYA, Sinan ŞAHIN*
}

\begin{abstract}
Developments in manufacturing technologies and new opportunities lead to reconsider the design of the spare part supply chains. In this paper, 3D printing technology, which is one of the most critical applications of industry 4.0 has been studied for examining new opportunities. Manufacturing facilities, 3D printing centers, warehouses, distribution centers have been taken into account in supply chain. Quantity of products, timing, technology to be used, assigned facility, investments and warehouse for product storage are considered as decision variables. The output of this study is to propose a mathematical model that minimizes the sum of production, distribution, and inventory holding costs. The main constraints of the model are the capacity of the manufacturing facilities \& 3D printing centers, warehouse areas, and demands. Inventory holding cost, unit transportation cost, production time and cost, needed space, distances between facilities, transportation time, bill of materials, demand in periods, and investment cost parameters have been used in a mathematical model and reached the optimum solution with branch and bound algorithm. Because of the nature of the problem, solution time takes longer when the problem size is larger. Therefore, in this paper, a unique Single Side Priority Based Algorithm (SSPBA) has been developed in genetic algorithm approach to find near optimum results.
\end{abstract}

Keywords: genetic algorithm; industry 4.0; spare part supply chain; 3D printing

\section{INTRODUCTION}

In 2017, the automotive sector accounted for about $5 \%$ of the world economy [1]. Again, according to 2017 data, 97 million vehicles were produced in the world. Approximately 1250000,000 vehicles are considered to be in use today [2]. High vehicle demand gives employment opportunity for millions of people in the world, clearly demonstrates the importance of the sector in different aspect. In the automotive sector, it has been revealed that after sales revenues have a significant effect on the company profits. In 2001, it was found that General Motors' profit after sales of $\$ 9$ billion was more than the profit from regular vehicle sales (150 billion dollars) [3]. This shows how the spare parts in the automotive sector have an impact on operating profitability and sustainability. Also, the surveys revealed that approximately $23 \%$ of the spare parts remained without sales, and on time delivery performance is $85 \%$ [4]. This data allows us to think that effective spare part supply chain management can have a positive impact on the company's annual profits and create a competitive advantage.

The organization of production and post-production activities is crucial for the continuity of this system. The breadth and diversity of the customer and service network, high and increasing vehicle demand, and developing manufacturing technologies show that the spare part supply chain should be reconsidered. In this study, a unique solution methodology will be introduced in the spare parts production and distribution network design.

\subsection{Literature Review}

In order to understand new trends and past studies in spare part logistics, papers, and thesis on distribution systems and spare part logistics have been searched. Most of the proposed solutions in those fields include mathematical models. Emerging technologies such as 3D printers, industry 4.0 components lead to think about new perspectives in the supply chain. It has been seen that there are studies related to additive manufacturing technics and applications in different fields, but there were limited studies on integration to supply chain.

An efficient 3D printed part ordering system has been presented. In the study, a cloud-based platform is used for analysing geometry of the part, preparing quotation, additive manufacturing and delivering the part [5]. The study is promising for advance industry 4.0 implementations.

Additive manufacturing has a positive effect of lead time reduction as well. It is reported that the 14-day period could be reduced to 3 days if the electronic components were repaired by the additive production method. Models of current and future situations are shared. Besides, a real case analysis was performed, and images were presented $[6,7]$.

Silva and Rezende evaluated the possible impact of additive production and $3 \mathrm{D}$ printers on production and their logistics. It was recommended to use the $3 \mathrm{D}$ printer to make prototypes, or for low volume production, instead of material movement, sending technical details will provide cost advantage in health industry. It was also mentioned that it would be more beneficial to carry out logistic activities without being exposed to environmental and restrictive procedures [8].

It has been stated that spare parts could be produced by means of rapid manufacturing techniques. In the study, production locations, storage areas, service points are shown in a network but it is limited. Although it is known that rapid manufacturing techniques allow for the production of spare parts, integrated supply chain work has not been done, and mathematical model has not been included to this work [9]

When the model size gets bigger, the elapsed time for the solution matters. In order to decrease solution time still having consistent results, there are many heuristic approaches that have been proposed in supply chain problems. One of them is the genetic algorithm (GA), which is used in this paper as well.

A heuristic approach based on a single-period, singlesource, multi-product, multi-stage supply chain design problem has been proposed. In the model suggested, it is 
not possible to see how the cost matrix has been created, its single period, and there is no backlog. In these conditions, it can be clearly seen that GA has the best performance indicators among heuristic methods in that study [10].

For new product development and management of the absolute inventory, a study has been published. In the paper, a priority-based algorithm has been implemented for small, medium, and large scales. The model is solved with Lingo and GA, and performance has been compared in order to overcome NP-hardness [11].

A mixed-integer linear programming (MILP) model is proposed for a multi-product four-stage flexible supply chain network design (SCND). This paper shows that GA is a useful tool when there is no other delivery mode in the supply chain [12].

After the literature search, it has been seen that there are combined studies in fields of the distribution systems $\&$ supply chains. There are also many studies using optimization technics such as mixed-integer programming and heuristics like genetic algorithms. However, we could not see any study that includes material planning, comparisons of emerging production methods such as 3D printing \& conventional production systems, allocation of goods production, and storage possibilities in different facilities to minimize the total cost of operations in the automotive industry.

\section{MODEL STUDY}

Performance expectations from an excellent spare part supply chain in summary; $98 \%$ customer demand coverage (average 93\%), 6 to 8 times inventory cycle per year (average 3-4), fulfil the order with 95\% performance in a day or less than a day (average 3-5 days) and logistics costs (outbound and storage) not exceeding $5 \%$ of the selling price (average $8 \%$ ) [13]. So that:

- In order not to lose the market share, the products must be ready in the required amount to respond to customer demand.

- Orders must be answered very quickly to ensure customer satisfaction.

- Shipment and storage costs should be minimized while the above items are met. A mathematical model has been developed with constraints, variables, and parameters in order to design a network that can provide improvements in these essential areas.

The automotive spare part supply chain starts with raw material producers and reaches to end-users with having various production centers, warehouses, and distribution centers. As can be seen in Figure 1, the model to be studied will be between additive manufacturing centers and distribution centers.

\subsection{Mathematical Model}

The notation, objective function, and constraints used in the developed model are given below. Seven sets used in the model:

Sets:

A: Set of additive manufacturing centers
$\mathrm{I}:$ Set of manufacturing centers

$\mathrm{S}:$ Set of warehouses

$\mathrm{K}$ : Set of distribution centers

$\mathrm{J}$ : Set of finished goods

$\mathrm{Y}:$ Set of semi-finished goods

$\mathrm{T}:$ Set of periods

The used parameters in the mathematical model are shown below.

Parameters:

$\mathrm{INV}_{\mathrm{JIT}}$ : Quantity of finished good " $j$ " in manufacturing center " $i$ " in $t$ period

INV2 $2_{\text {YIT }}$ : Quantity of semi-finished good " $y$ " in manufacturing center " $i$ " in $t$ period

INV $3_{\text {YAT }}$ : Quantity of semi-finished good " $y$ " in the additive manufacturing center" $a$ " in $t$ period

$\mathrm{INV}_{\text {JST }}$ : Quantity of finished good " $j$ " in warehouse " $s "$ in $t$ period

INV5 $5_{\text {YST }}$ : Quantity of semi-finished good " $y$ " in warehouse " $s$ " in $t$ period

$\mathrm{CP1}_{\mathrm{I}}$ : Production cost in manufacturing center" $i$ "

$\mathrm{CP} 2_{\mathrm{A}}$ : Production cost in additive manufacturing center " $a$ "

$\mathrm{CTRF}_{\mathrm{J}}$ : Unit transportation cost of finished good " $j$ "

$\mathrm{CTRS}_{\mathrm{Y}}$ : Unit transportation cost of semi-finished good " $y$ "

$\mathrm{CFXM}_{\mathrm{I}}$ : Cost of opening a manufacturing center $i "$

$\mathrm{CFXP}_{\mathrm{A}}$ : Cost of opening an additive manufacturing center" $a$ "

$\mathrm{CFXW}_{\mathrm{S}}$ : Cost of opening a warehouse " $s "$

$\mathrm{CAPM}_{\mathrm{IT}}$ : Capacity of manufacturing center " $i$ " in $t$ period

$\mathrm{CAPA}_{\mathrm{AT}}$ : Capacity of additive manufacturing center " $a$ " in $t$ period

$\mathrm{CAPW}_{\mathrm{ST}}$ : Capacity of warehouse " $s "$ in $t$ period

$\mathrm{DEM}_{\mathrm{JKT}}$ : Demand of finished good " $j$ " for distribution center " $k$ " in $t$ period

$\mathrm{TIMF}_{\mathrm{JI}}$ : Production time of finished good " $j$ " in manufacturing center " $i$ "

$\mathrm{TIM}_{\mathrm{YI}}$ : Production time of semi-finished good " $y "$ in manufacturing center" $i "$

TIM2 ${ }_{\mathrm{YA}}$ : Production time of semi-finished good " $y$ " in additive manufacturing center " $a$ "

$\mathrm{SPAF}_{\mathrm{J}}$ : Needed space for finished good " $j "$

SPAS $_{Y}:$ Needed space for semi-finished good " $y "$

$\mathrm{CIH1}_{\mathrm{I}}$ : Inventory holding cost for manufacturing center " $i "$

$\mathrm{CIH} 2_{\mathrm{A}}$ : Inventory holding cost for the additive manufacturing center " $a$ "

$\mathrm{CIH}_{\mathrm{S}}$ : Inventory holding cost in warehouse " $s "$ 
$\mathrm{DIS1}_{\mathrm{IS}}:$ Distance between manufacturing center" $i "$ and warehouse" $s "$

$\mathrm{DIS} 2_{\mathrm{AI}}$ : Distance between additive manufacturing center " $a$ " and manufacturing center" $i$ "

$\mathrm{DIS}_{\mathrm{SK}}$ : Distance between warehouse " $s$ " and distribution center" $k$ "

$\mathrm{LT}_{\mathrm{IS}}$ : Lead time from manufacturing center " $i$ " to warehouse " $s "$

LT2 ${ }_{\mathrm{AI}}$ : Lead time from additive manufacturing center " $a$ " to manufacturing center " $i$ "

$\mathrm{LT}_{\text {SK }}$ : Lead time from warehouse " $s$ " to distribution center" $k$ "

$\mathrm{BOM}_{J Y}$ : Needed quantity of semi-finished good " $y$ " for finished good " $j "$

The variables of the model given below are related with the produced quantities, transported quantities, and opened facilities.

Variables:

$\mathrm{XPF}_{\mathrm{IJT}}$ : Production quantity of finished good " $j "$ in manufacturing center " $i$ " in period " $t$ "

$\mathrm{XPS1}_{\mathrm{IYT}}$ : Production quantity of semi-finished good " $y$ " produced in manufacturing center " $i$ " in period " $t$ "
$\mathrm{XPS} 2_{\mathrm{AYT}}$ : Production quantity of semi-finished good " $y$ " produced in additi

$\mathrm{XLOG}_{\mathrm{JSKT}}$ : Transportation quantity of finished good "j" from warehouse " $s$ " to distribution center " $k$ " in period " $t$ "

XLOG2 $_{\text {YAIT }}$ : Transportation quantity of semi finished good $" y$ " from add. man. center " $a$ " to manufacturing center " $i$ " in period " $t$ "

$\mathrm{XLOG}_{\text {YIST }}$ : Transportation quantity of semi finished good " $y$ "from manufacturing center " $i$ " to warehouse $" s "$ in period " $t "$

$\mathrm{XLOG}_{\text {JIST }}$ : Transportation quantity of finished good "j" from manufacturing center " $i$ " to warehouse $" s "$ in $t$ period

XLOG5 $_{\text {YSIT }}$ : Transportation quantity of semi-finished good $" y$ " from warehouse " $s$ " to manufacturing center " $i$ " in $t$ period

$\mathrm{OPM}_{\mathrm{I}}$ : If the manufacturing center $\mathrm{i}$ is opened 1 , otherwise 0 $\mathrm{OPA}_{\mathrm{A}}$ : If the additive manufacturing center is opened 1 , otherwise 0

$\mathrm{OPW}_{\mathrm{S}}$ : If the warehouse $\mathrm{s}$ is opened 1 , otherwise 0

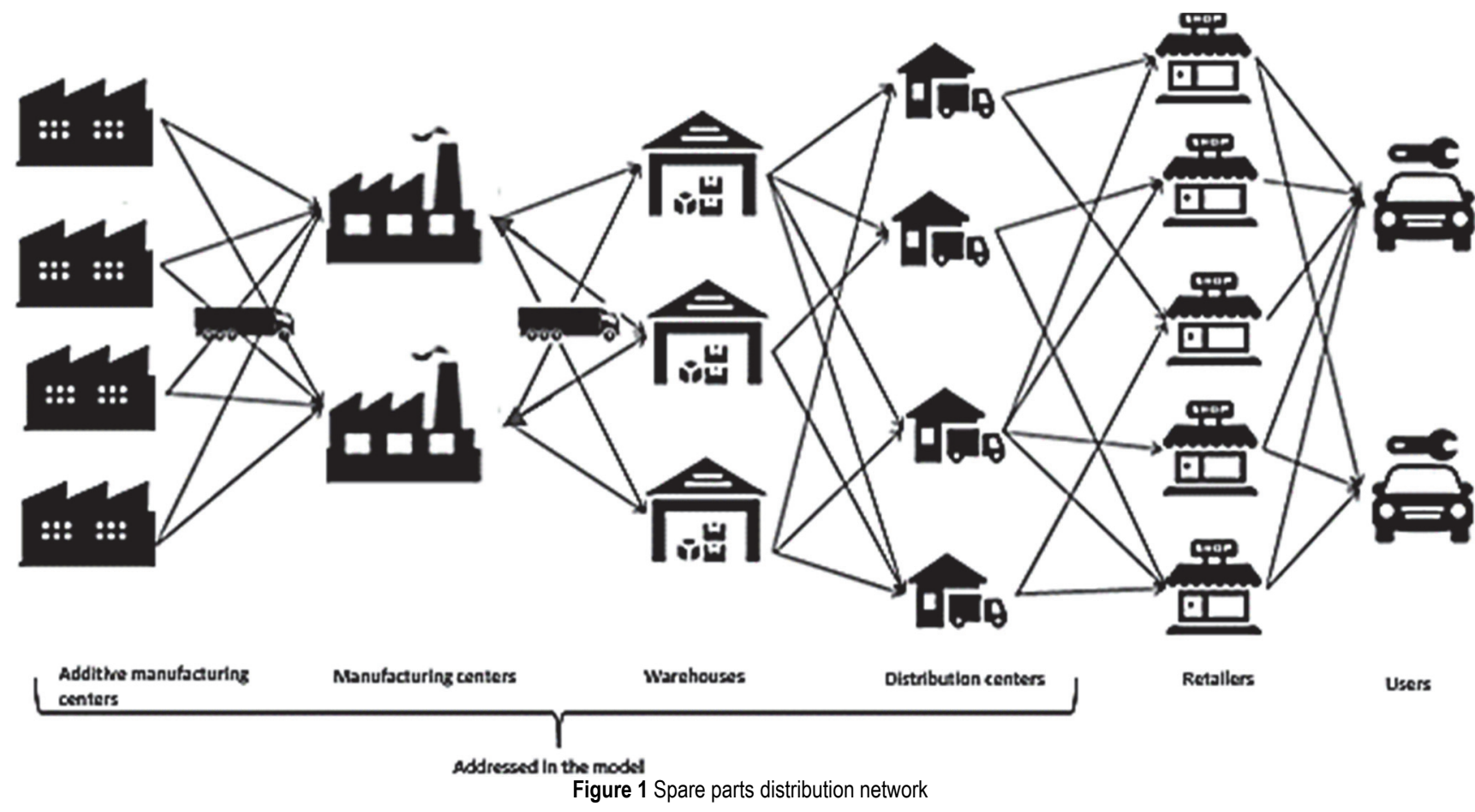

Objective function:

Min. Prod. cost + Tran. cost + Inv hold. cost +

+ Investing cost

Prod. cost $=\left(\mathrm{CP1}_{\mathrm{I}} \times \mathrm{TIMF}_{\mathrm{JI}} \times \mathrm{XPF}_{\mathrm{IJT}}\right)+$

$+\left(\mathrm{CP}_{\mathrm{I}} \times \mathrm{TIM}_{\mathrm{YI}} \times \mathrm{XPS1}_{\mathrm{IYT}}\right)+$
Tran. cost $=\left(\mathrm{DISl}_{\mathrm{IS}} \times \mathrm{XLOG}_{\mathrm{JIST}} \times \mathrm{CTRF}_{\mathrm{J}}\right)+$

$\left(\mathrm{DIS}_{\mathrm{AI}} \times \mathrm{XLOG}_{\mathrm{YAIT}} \times \mathrm{CTRS}_{\mathrm{Y}}\right)+$

$+\left(\mathrm{DIS}_{\mathrm{SK}} \times \mathrm{XLOG}_{\mathrm{JSKT}} \times \mathrm{CTRF}_{\mathrm{J}}\right)+$

$+\left(\mathrm{DIS1}_{\mathrm{IS}} \times \mathrm{CTRS}_{\mathrm{Y}} \times\left(\mathrm{XLOG} 3_{\mathrm{YIST}}+\mathrm{XLOG} 5_{\mathrm{YSIT}}\right)\right)$

$+\left(\mathrm{CP} 2_{\mathrm{A}} \times \mathrm{TIM} 2_{\mathrm{YA}} \times \mathrm{XPS} 2_{\mathrm{AYT}}\right)$ 
Inv hold. cost $=$

$\left(\mathrm{CIH1}_{\mathrm{I}}\left(\mathrm{INV}_{\mathrm{JIT}} \times \mathrm{SPAF}_{\mathrm{J}}+\mathrm{INV}_{\mathrm{YIT}} \times \mathrm{SPAS}_{\mathrm{Y}}\right)\right)+$

$+\left(\mathrm{CIH} 2_{\mathrm{A}} \times \mathrm{INV}_{\mathrm{YAT}} \times \mathrm{SPAS}_{\mathrm{Y}}\right)+$

$+\left(\mathrm{CIH} 3_{\mathrm{S}} \times\left(\mathrm{INV}_{\mathrm{JST}} \times \mathrm{SPAF}_{\mathrm{J}}+\mathrm{INV}_{\mathrm{YST}} \times \mathrm{SPAS}_{\mathrm{Y}}\right)\right)$

Investing cost $=\left(\mathrm{CFXM}_{\mathrm{I}} \times \mathrm{OPM}_{\mathrm{I}}\right)+$

$+\left(\mathrm{CFXP}_{\mathrm{A}} \times \mathrm{OPA}_{\mathrm{A}}\right)+\left(\mathrm{CFXW}_{\mathrm{S}} \times \mathrm{OPW}_{\mathrm{S}}\right)$

Constraints:

$$
\begin{aligned}
& \mathrm{INV}_{\mathrm{JIT}}=\mathrm{INV} 1_{\mathrm{JIT}-1}+\mathrm{XPF}_{\mathrm{IJT}}-\sum_{1}^{\mathrm{s}} \mathrm{XLOG} 4_{\mathrm{JIST}}, \forall j, i, t(6) \\
& \mathrm{INV} 2_{\mathrm{YIT}}=\mathrm{INV} 2_{\mathrm{YIT}-1}+\mathrm{XPS} 1_{\mathrm{YIT}}-\sum_{1}^{\mathrm{s}} \mathrm{XLOG} 3_{\mathrm{YIST}}- \\
& -\sum_{1}^{j}\left(\mathrm{XPF}_{\mathrm{IJT}} \times \mathrm{BOM}_{\mathrm{JY}}\right)+\sum_{1}^{\mathrm{s}} \mathrm{XLOG} 5_{\mathrm{YSIT}-\mathrm{LT} 1_{\mathrm{IS}}}+ \\
& +\sum_{1}^{\mathrm{a}} \mathrm{XLOG}_{Y}{ }_{\mathrm{YIIT}+L T 2_{A I}}, \forall y, i, t \\
& \mathrm{INV} 3_{\mathrm{YAT}}=\mathrm{INV}_{\mathrm{YAT}-1}+X P S 2_{Y A T}- \\
& -\sum_{1}^{\mathrm{i}} \mathrm{XLOG} 2_{\mathrm{YAIT}}, \forall y, a, t
\end{aligned}
$$$$
\mathrm{INV}_{\mathrm{JST}}=\mathrm{INV}_{\mathrm{JST}-1}+\sum_{1}^{\mathrm{i}} \mathrm{XLOG}_{\mathrm{JIST}-\mathrm{LT} 1_{\mathrm{IS}}}-
$$$$
-\sum_{1}^{\mathrm{k}} \mathrm{XLOG1}_{\mathrm{JSKT}}, \forall j, s, t
$$$$
\mathrm{INV}_{\mathrm{YST}}=I N V 5_{Y S T-1}+\sum_{1}^{\mathrm{i}} \mathrm{XLOG} 3_{\mathrm{YIST}-\mathrm{LT} 1_{\mathrm{IS}}}-
$$$$
-\sum_{1}^{\mathrm{i}} \mathrm{XLOG} 5_{\mathrm{YSIT}}, \forall y, s, t
$$$$
\mathrm{DEM}_{\mathrm{JKT}} \leq \sum_{1}^{\mathrm{s}} \mathrm{XLOG1}_{\mathrm{JSKT}-\mathrm{LT} 3 \mathrm{SK}}, \forall j, k, t
$$$$
\left(\mathrm{CAPM}_{\mathrm{IT}} \times \mathrm{OPM}_{\mathrm{I}}\right) \geq\left(\begin{array}{l}
\sum_{1}^{j}\left(\mathrm{XPF}_{\mathrm{IJT}} \times \mathrm{TIMF}_{\mathrm{JI}}\right)+ \\
+\sum_{1}^{y}\left(\mathrm{XPS1}_{\mathrm{IYT}} \times \mathrm{TIM}_{\mathrm{YI}}\right)
\end{array}\right), \forall i,
$$

$\left(\mathrm{CAPW}_{\mathrm{ST}} \times \mathrm{OPW}_{\mathrm{S}}\right) \geq\left(\begin{array}{l}\sum_{1}^{j}\left(\mathrm{INV}_{\mathrm{JST}} \times \mathrm{SPAF}_{\mathrm{J}}\right)+ \\ +\sum_{1}^{y}\left(\mathrm{INV}_{\mathrm{YST}} \times \mathrm{SPAS}_{\mathrm{Y}}\right)\end{array}\right), \forall s, t($

$\left(\mathrm{CAPA}_{\mathrm{AT}} \times \mathrm{OPA}_{\mathrm{A}}\right) \geq \sum_{1}^{y}\left(\mathrm{XPS} 2_{\mathrm{AYT}} \times \mathrm{TIM}_{\mathrm{YA}}\right), \forall a, t$ 
Table 2 Quantities of semi-finished parts per products

\begin{tabular}{|c|c|c|c|c|c|}
\hline BOM $_{\mathrm{IY}}$ & 1 & 2 & 3 & 4 & 5 \\
\hline 1 & 1 & 1 & 1 & 0 & 0 \\
\hline 2 & 1 & 1 & 0 & 0 & 0 \\
\hline 3 & 0 & 0 & 1 & 1 & 1 \\
\hline
\end{tabular}

The data belonging to parameters described under Section 2.1 are shown in Tab. 3 to Tab. 10. Process data are in minutes; demand values are in quantities, area data are in square meter, the currency is taken as Euro.

Table 3 Weekly demands for products

\begin{tabular}{|c|c|c|c|c|c|c|}
\hline DEM $_{\text {JKT }}$ & 1 & 2 & 3 & 4 & 5 & 6 \\
\hline $\mathrm{K}: 1$ & 0 & 0 & 1500 & 2000 & 500 & 2000 \\
\hline $\mathrm{K}: 1$ & 0 & 0 & 1000 & 1000 & 1000 & 1000 \\
\hline $\mathrm{K}: 1$ & 0 & 0 & 1000 & 2000 & 2000 & 2000 \\
\hline $\mathrm{K}: 2$ & 0 & 0 & 2000 & 3000 & 1000 & 3000 \\
\hline $\mathrm{K}: 2$ & 0 & 0 & 1000 & 2000 & 500 & 2000 \\
\hline $\mathrm{K}: 2$ & 0 & 0 & 1000 & 3000 & 1000 & 3000 \\
\hline $\mathrm{K}: 3$ & 0 & 0 & 500 & 1000 & 1000 & 1000 \\
\hline $\mathrm{K}: 3$ & 0 & 0 & 2000 & 1000 & 1000 & 1000 \\
\hline $\mathrm{K}: 3$ & 0 & 0 & 1000 & 1000 & 1000 & 1000 \\
\hline
\end{tabular}

Table 4 Plant capacities

\begin{tabular}{|c|c|c|c|}
\hline \multicolumn{5}{|c|}{ Table 4 Plant capacities } \\
\hline CAPM $_{\mathrm{IT}}$ & 20000 & 8000 & 2000 \\
\hline CAPW $_{\mathrm{ST}}$ & 5000 & 15000 & 5000 \\
\hline CAPA $_{\mathrm{AT}}$ & 400 & 800 & 1000 \\
\hline
\end{tabular}

Table 5 Investment cost

\begin{tabular}{|c|c|c|c|}
\hline \multicolumn{5}{|c}{ Table 5 Investment cost } \\
\hline CFXM $_{\mathrm{I}}$ & 10000 & 2000 & 8000 \\
\hline $\mathrm{CFXP}_{\mathrm{A}}$ & 200 & 100 & 100 \\
\hline $\mathrm{CFXW}_{\mathrm{S}}$ & 7000 & 1000 & 2000 \\
\hline
\end{tabular}

\begin{tabular}{|c|c|} 
Table 6 Inventory holding cost \\
\begin{tabular}{|c|c|}
\hline $\mathrm{CIH} 1_{\mathrm{I}}$ & 2 \\
\hline $\mathrm{CIH} 2_{\mathrm{A}}$ & 50000 \\
\hline $\mathrm{CIH} 3_{\mathrm{S}}$ & 1 \\
\hline
\end{tabular}
\end{tabular}

Table 7 Finished product and semi-finished production cycle times

\begin{tabular}{|c|c|c|c|c|c|}
\hline TIM1 $1_{\mathrm{YI}}$ & 0,1 & 0,2 & 0,1 & 11 & 0,3 \\
\hline TIM2 & 1 & 2 & 1 & 1 & 3 \\
\hline TIM3 & 1 & 0,5 & 1 & - & - \\
\hline
\end{tabular}

Table 8 Shipping costs per piece

\begin{tabular}{|c|c|c|c|c|c|}
\hline CTRS $_{\mathrm{Y}}$ & 0,1 & 0,2 & 0,1 & 0,1 & 0,3 \\
\hline $\mathrm{CTRF}_{\mathrm{J}}$ & 2 & 1 & 3 & - & - \\
\hline
\end{tabular}

Table 9 Unit production costs in facilities

\begin{tabular}{|c|c|c|c|}
\hline $\mathrm{CP} 1_{\mathrm{I}}$ & 10 & 5 & 7 \\
\hline $\mathrm{CP} 2_{\mathrm{A}}$ & 7 & 5 & 5 \\
\hline
\end{tabular}

Table 10 Areas covered by products
\begin{tabular}{|c|c|c|c|c|c|}
\hline SPAS $_{\mathrm{Y}}$ & 0,1 & 0,2 & 0,1 & 0,1 & 0,3 \\
\hline SPAF $_{\mathrm{J}}$ & 2 & 1 & 3 & - & - \\
\hline
\end{tabular}

Fig. 3 shows the connections between semi-finished goods and finished goods, which are inspired by their drawings. For example, finished good 1 is constituted from semi-finished goods 1,2 , and 3.

Level-1:

Semi finished goods
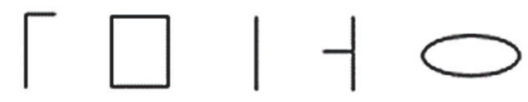

Level-2:

Finished goods
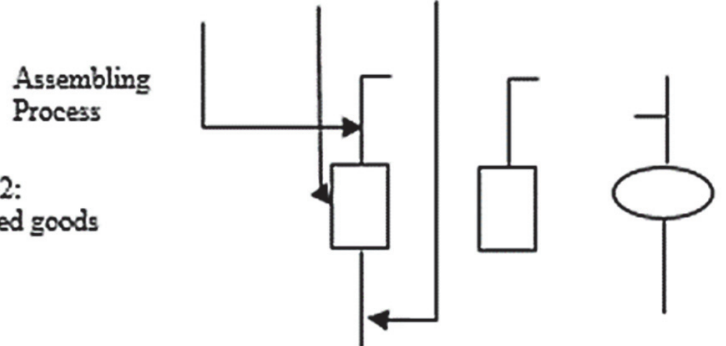

Figure 32D illustration finished products and semi-finished products

Table 11 Stage- 1 in sub-chromosome

\begin{tabular}{|c|c|c|c|c|c|c|c|c|c|c|c|c|c|c|c|c|c|c|c|c|c|c|c|c|c|c|c|c|c|c|c|c|c|c|c|c|c|c|c|c|c|c|c|c|}
\hline \multirow{4}{*}{$\begin{array}{r}t=6 \\
Y \\
A, 1 \\
*\end{array}$} & \multicolumn{44}{|c|}{ STAGE 1} \\
\hline & \multicolumn{9}{|c|}{ Semi Finishod Good : 1} & \multicolumn{9}{|c|}{ Semi Finished Good : 2} & \multicolumn{9}{|c|}{ Seml Finiahod Good : 3} & \multicolumn{9}{|c|}{ Seml Finiahod Good : 4} & \multicolumn{8}{|c|}{ Seml Finiahed Good is } \\
\hline & \multicolumn{6}{|c|}{ Suppliers } & \multicolumn{3}{|c|}{ Plants } & \multicolumn{6}{|c|}{ Supplicers } & \multicolumn{3}{|c|}{ Plants } & \multicolumn{6}{|c|}{ Suppliers } & \multicolumn{3}{|c|}{ Plants } & \multicolumn{6}{|c|}{ Suppliers } & \multicolumn{3}{|c|}{ Plants } & \multicolumn{6}{|c|}{ Suppliers } & \multicolumn{2}{|c|}{ Plants } \\
\hline & 1 & 2 & 3 & 4 & 5 & 6 & 1 & 2 & 3 & 1 & 2 & 3 & 4 & 5 & 6 & 1 & 2 & 3 & 1 & 2 & 3 & 4 & s) & 6 & 1 & 2 & 3 & 1 & 2 & 3 & 4 & s & 6 & 1 & 2 & 3 & 1 & 2 & 3 & 4 & s & 6 & & \begin{tabular}{|l|l|}
2 & 3 \\
\end{tabular} \\
\hline R & 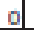 & 0 & 0 & & 0 & 0 & 2 & & 3 & 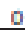 & o & o & o & o & 0 & F & 4 & 6 & 0 & ol & 0 & 0 & & 0 & 9 & 7 & 81 & 0 & & 0 & & 이 & & 11. & & 12 & 0 & & o] & & 의 & & & $15 \mid 14$ \\
\hline
\end{tabular}

\subsection{Alternative Solution Method}

The introduced integrated model for the proposed supply chain network is a mixed-integer programming model with several constraints. Solving these models in a reasonable time, especially in real-world instances, is the main challenge in most researches. When the model size is getting larger, it is hard to solve with applying exact solution algorithms. In this paper, we propose to use a genetic algorithm (GA) solution method to reach near optimum results.

\subsubsection{Representation of GA Approach}

One of the earliest and simplest representations has been made by G. A. Vignaux and Z. Michalewicz considering a genetic algorithm for the linear transportation problem [14]. They used edge-based encoding and binary system for assignments [10]. In both studies, total facility capacities and demand are equal. If there is a deviation, it is covered by a dummy facility or demand, which is different from the model we propose. In order not to use dummy facility or demand, there is supposed to be a backlog in the supply chain when there is more than one period if total capacity is sufficient to cover whole demand in the supply chain. In our study, there is no priority for customer demand satisfying; both of them have the top priority equally, which is different from other studies. Another difference, using zeros for genes on the left section of the sub-chromosomes, which helps the algorithm to find the possible lowest cost for the customer in case of demand \& capacity inequality. The mentioned supply chain design in the previous section must be eligible to use genetic algorithm, so that it needs to be converted to a transportation tree in this specific case. Because there is more than one possible place to produce semi-finished goods, this is why M1, M2, and M3 are shared for both stages, and their capacities need to be updated in each iteration. The converted supply chain illustration can be seen in Fig. 4.

The sub-chromosome for one period consists of three stages in this case, which can be seen in Tab. 11, Tab. 12, and Tab. 13. So that the whole sub-chromosome can be multiplied for six periods. 
Add. Man. \& Man. Centers Manufacturing Centers Warehouses Distribution Centers

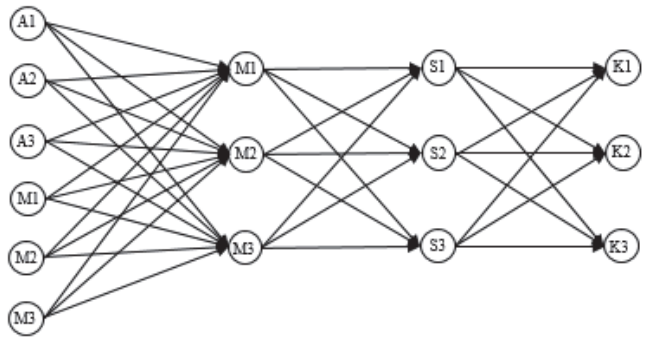

Figure 4 Transportation tree for GA

Table 12 Stage-2 in sub-chromosome

\begin{tabular}{|c|c|c|c|c|c|c|c|c|c|c|c|c|c|c|c|c|c|c|}
\hline$t=6$ & \multicolumn{18}{|c|}{ STAGE 2} \\
\hline J & \multicolumn{6}{|c|}{ FG I } & \multicolumn{6}{|c|}{ FG 2} & \multicolumn{6}{|c|}{ FG 3} \\
\hline 15 & \multicolumn{3}{|c|}{ Plant: } & \multicolumn{3}{|c|}{ Warchouse } & \multicolumn{3}{|c|}{ Plant } & \multicolumn{3}{|c|}{ Warchouse } & \multicolumn{3}{|c|}{ Plant } & \multicolumn{3}{|c|}{ Warchouse } \\
\hline 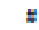 & 1 & 2 & 3 & 1 & 2 & 3 & 1 & 2 & 3 & 1 & 2 & 3 & 1 & 2 & 3 & 1 & 2 & 3 \\
\hline R & 0 & 0 & 0 & 2 & 3 & 1 & 0 & 0 & 0 & 4 & 6 & 8 & 0 & 0 & 0 & 9 & 8 & $\pi$ \\
\hline
\end{tabular}

Table 13 Stage-3 in sub-chromosome

\begin{tabular}{|c|c|c|c|c|c|c|c|c|c|c|c|c|c|c|c|c|c|c|}
\hline$t=6$ & \multicolumn{18}{|c|}{ STAGE 3} \\
\hline & \multicolumn{6}{|c|}{ FG 1} & \multicolumn{6}{|c|}{ FG 2} & \multicolumn{6}{|c|}{ FG 3} \\
\hline $5, x$ & \multicolumn{3}{|c|}{ Warchouse } & \multicolumn{3}{|c|}{ D.Center } & \multicolumn{3}{|c|}{ Warehoure } & \multicolumn{3}{|c|}{ D.Center } & \multicolumn{3}{|c|}{ Warchoure } & \multicolumn{3}{|c|}{ D.Center } \\
\hline * & 1 & 2 & 3 & 1 & 2 & 3 & 1 & 2 & 3 & 1 & 2 & 3 & 1 & 2 & 3 & 1 & 2 & 3 \\
\hline $\mathbf{R}$ & o & 0 & 0 & 2 & 1 & 3 & 0 & 0 & 0 & 4 & 6 & & 0 & 0 & 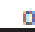 & 7 & & 8 \\
\hline
\end{tabular}

The length of the sub-chromosome is equal to the sum of Stage-1 $|Y| \cdot(|A|+|I|)$, Stage-2 $|J| \cdot(|I|+|S|)$ and Stage-3 $|J| \cdot(|S|+|K|)$. And the whole chromosome's length can be formulated as $|T| \cdot(|Y| \cdot(|A|+|I|)+|J| \cdot(|I|+|S|)+|J| \cdot(|S|$ $+|K|))$.

To implement an encoding \& decoding methodology, the cost calculation for each allocation becomes essential. The cost matrix needs to be accurate to find out the best matches. The best and most suitable matches in cost matrix help to minimize total cost. Cost matrix can be calculated in different ways if there is a certain break-even point when there are fixed costs. In our case, the volume is quite enough to distribute fixed costs among the demanded parts. So that total costs must be calculated, including fixed and variable costs, which are derived from parameters given. The cost matrix for each stage can be seen in Tab. 14, Tab. 15, and Tab. 16.

Table 14 Cost matrix between add.mancenters and manufacturing centers

\begin{tabular}{|c|c|c|c|c|c|c|}
\hline$I-A$ & 1 & 2 & 3 & 4 & 5 & 6 \\
\hline 1 & 10,1 & 17,0 & 19,2 & 12,3 & 18,8 & 16,3 \\
\hline 2 & 22,1 & 5,0 & 16,4 & 20,8 & 14,3 & 16,3 \\
\hline 3 & 21,6 & 13,7 & 7,7 & 21,3 & 9,3 & 9,8 \\
\hline
\end{tabular}

Table 15 Cost matrix between manufacturing centers and warehouses

\begin{tabular}{|c|c|c|c|}
\hline \multicolumn{4}{|c|}{ Table 15 Cost matrix between manufacturing centers and warehouses } \\
\hline 1 & 1 & 2 & 3 \\
\hline 2 & 14,1 & 23,1 & 17,6 \\
\hline 3 & 13,0 & 10,5 & 14,0 \\
\hline
\end{tabular}

Table 16 Cost matrix between warehouses and distribution centers

\begin{tabular}{|c|c|c|c|}
\hline$S-K$ & 1 & 2 & 3 \\
\hline 1 & 3,7 & 3,7 & 15,2 \\
\hline 2 & 11,0 & 6,0 & 5,5 \\
\hline 3 & 5,1 & 4,6 & 11,6 \\
\hline
\end{tabular}

\subsubsection{Single Side Priority Based Algorithm}

Priority based decoding algorithm is used for defining the allocations between depots and sources for one period when capacity and demand are equal in each echelon [11].
The same method can be seen in a genetic algorithm application for supply chain configuration with new product development [15]. In both papers, because of no restriction with periods and backlog coverage, priority based encoding \& decoding algorithm enables initialization from any point of the arc in the transportation tree. But that can be criticized, in real cases in the automotive industry, backlog needs to be considered, and capacity needs to be managed for the whole time horizon which is ideally three months, in order to put action plans in place. To adapt priority based encoding \& decoding methodology into this form of supply chain, demand and backlog can be managed from a single side when allocations are done to minimize solution time. So, we propose a different solution system that is triggered by the demand to find the best supplier for itself in each iteration. And we call this algorithm Single Side Priority Based Algorithm, shortly SSPBA. General solving procedure and of sub-procedures can be seen in Fig. 5, Fig. 6, Fig. 7, and Fig. 8.

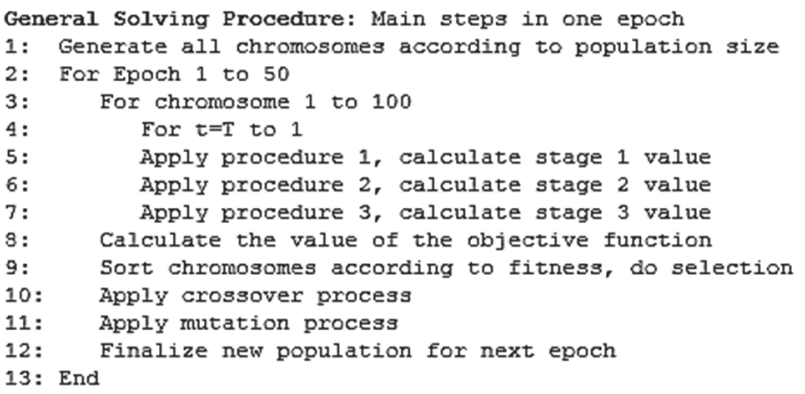

Figure 5 Decoding of SSPBA for multi-period \& product

Prodecure 1: Decoding of the stage 3

Input: Demand, capacity, sub-chromosome, M(very big value) output: Amount of product shipped to DC

1: Find max. random value (R) for distributers

2: Use cost matrix to find most suitable warehouse

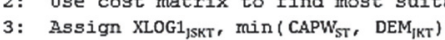

3: Assign XIOG1 $1_{1 S K T}, \min$ (

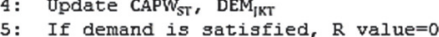

5: If there is no capacity/demand left for any, put $M$ into related If there is no capacity/demand left for any, put $M$ into
cost matrix items to avoid mismatches in next iteration

7: If total $\sum \mathrm{DEM}_{\mathrm{HKT}}>\sum \mathrm{CAPW}_{\mathrm{ST}}$, assign backlog

8: Add backlog to $\mathrm{DEM}_{\mathrm{IKT}-1}$

9: Calculate the cost

10: End

Figure 6 Procedure 1

Procedure 2: Decoding of the stage 2

Input: Demand, capacity, sub-chromosome, M(very big value) Ontput: Amount of product shipped to $\mathrm{wH}$

1: Find max. random value (R) for warehouses

2: Use cost matrix to find most suitable manufacturing center

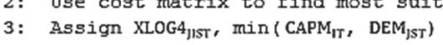

4: Update $\mathrm{CAPM}_{\mathrm{TT}}, \mathrm{DEM}_{\mathrm{IST}}$

5: If demand is satisfied, $R$ value $=0$

6: If there is no capacity/demand left for any, put $M$ into related cost matrix items to avoid mismatches in next iteration

: If total $\sum \mathrm{DEM}_{\mid \mathrm{ST}}>\sum \mathrm{CAPM}_{\mathrm{n}}$, assign backlog

8: Add backlog to $\mathrm{DEM}_{\mathrm{IST}-1}$

9: Calculate the cost

10: End

Figure 7 Procedure 2

Procedure 3: Decoding of the stage 1

Input: Demand, capacity, sub-chronosome, M(very big value)

Output: Amount of semi-finished good shipped to MC

1: Find max. random value(R) for manufacturing centers

2: Use cost matrix to find best additiveman.smanufacturing center

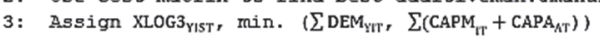

4: Update $\sum\left(\mathrm{CAPM}_{\mathrm{Ir}}+\mathrm{CAPA}_{A T}\right), \sum \mathrm{DEM}_{\mathrm{YIT}}$

5: If demand is satisfied, $R$ value $=0$

6: If there is no capacity/demand left for any, put $M$ into related cost matrix items to avoid mismatches in next iteration

: If $\sum \mathrm{DEM}_{\mathrm{VIT}}>\sum\left(\mathrm{CAPM}_{\mathrm{IT}}+\mathrm{CAPA}_{\mathrm{Ar}}\right)$, assign backlog

8: Add backlog to DEM YIT-1

9: Calculate the cost

10: End

Figure 8 Procedure 3 


\subsubsection{Solution Procedure}

Initial Population is randomly created in the proposed model. Various initializations can be seen in papers if the idea cuts solution time relatively depending on the problem. Size and initializations need to be tailored for the problems. In our work, the population is consisting of 100 individuals and the size remains the same through iterations.

Fitness Function gives tracking and progressing opportunities for better results in heuristic approaches. It can be either targeted for cost reduction/minimization or profit maximization. In GA, when the initial population is created, chromosomes are calculated as designed in the math model to see which parents are most adaptive in its environment and eligible for the creation of the next generation. In our case, the algorithm is looking to minimize the total cost of the chain. So, chromosomes that are creating the lowest costs in fitness function tend to carry on their genes for the next generations.

The Selection process directly effects solution time in GA. Once the initial population is created, the quality of the chromosome needs to be checked with fitness function and sorted. In the selection process, we propose elitism ratio is $4 \%$ so that the best four chromosomes can be picked for next-generation, and we set $10 \%$ spare places for having a chance to create random chromosomes in the next generation. The rest of the places in the next generation is filled with children which are coming from paired parents. Parents are matched with the ranking method considering Pareto rule. The parent has a higher rank (top 20\%), gets a much bigger chance to match with other chromosomes.
Crossover is a tool to enlarge solution clusters to find global optimum results in the defined model once parents are selected in the current population. It enables to mix specified segments or sub-segments in chromosomes to inject possible good genes to others. The mixing ratio or strategy is depending on population size. To optimize crossover process, it is important to utilize chromosomes that have better rank right after fitness function evaluation, as mentioned in the selection process. In our methodology, differently from other studies, we propose a two-level crossover process; firstly, applying crossover in between segments and secondly applying it in periods to ensure if the characters of the assignments are similar between periods due to the nature of the problem. Since each period's genes are independent, in case of good sort the genes are accumulated in one period; this can be tested by means of global crossover operator via applying the same formations for other periods as well. Crossover possibilities can be seen in Fig. 9.

Global Chromosome:

P1: $G_{1}-t_{1}, G_{2-} t_{2}, G_{3}-t_{3}, G_{4}-t_{4}, G_{5}-t_{5}, G_{6}-t_{6}$

P2: $G_{7}-t_{1}, G_{8}-t_{2}, G_{9}-t_{3}, G_{10}-t_{4}, G_{11}-t_{5}, G_{12}-t_{6}$

Global Crossover:

$$
\begin{aligned}
& G_{2}-t_{1}, G_{2}-t_{2}, G_{2}-t_{3}, G_{2}-t_{4}, G_{2}-t_{5}, G_{2}-t_{6} \\
& G_{3}-t_{1}, G_{3}-t_{2}, G_{3}-t_{3}, G_{3}-t_{4}, G_{3}-t_{5}, G_{3}-t_{6} \\
& G_{4}-t_{1}, G_{4}-t_{2}, G_{4}-t_{3}, G_{4}-t_{4}, G_{4}-t_{5}, G_{4}-t_{6} \\
& G_{5}-t_{1}, G_{5}-t_{2}, G_{5}-t_{3}, G_{5}-t_{4}, G_{5}-t_{5}, G_{5}-t_{6} \\
& G_{6}-t_{1}, G_{6}-t_{2}, G_{6}-t_{3}, G_{6}-t_{4}, G_{6}-t_{5}, G_{6}-t_{6}
\end{aligned}
$$
$\mathrm{t}=6$
Stage-1
Stage-2
Stage-3

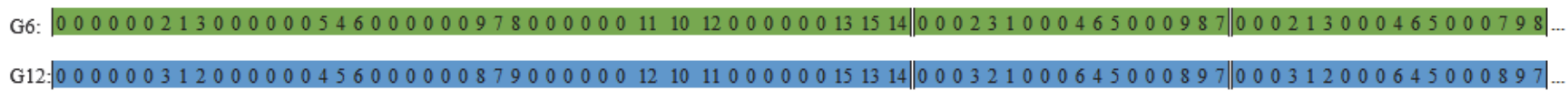

$\mathrm{C} 1: 000000213000000546000000978000000111012000000131514|000321000645000897| 000213000465000798 \mid \ldots$

$\mathrm{C} 2: 0000000213000000054600000000978000000011101200000000131514|| 00023310000465000987$ |0003

$\mathrm{C} 3:|0000003120000004560000000879000000012101100000000151314||00023310000465000987| 000312000645000897 \mid \ldots$

C4: $000000031200000045600000008790000001210110000000151314|000321000645000897 \| 000213000465000798| \ldots$

$\mathrm{C} 5: 000000213000000546000000097800000001110120000000131514|00003210000645000897| 000312000645000897 \mid \ldots$

C6: $0000000312000000456000000087900000001210110000000151314|0000231000465000987| 000213000465000798$.

Figure 9 An illustration of crossover operator

$\mathrm{t}=6$ Stage-1 Stage-2 Stage-3

G1: $000000213000000546000000978000000111012000000131514|000231000465000987| 000213000465000798$

G7: $000000031200000045600000008790000001210110000000151314 \mid 000321000645000897 \| 000312000645000897$.

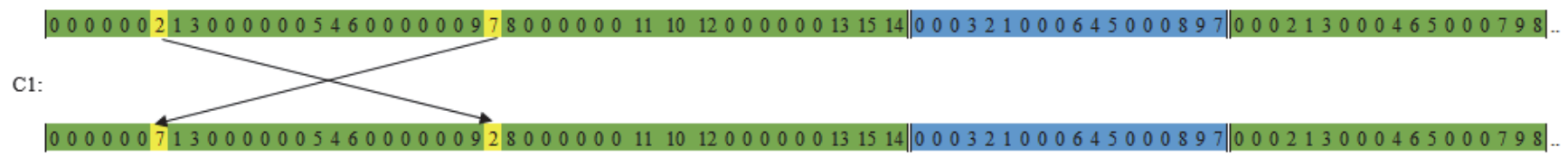

Figure 10 An illustration of mutation process

Mutation is used for swapping genes in defined subsegments after the crossover process in order to increase finding better solutions in the next generations. It generally does not give a more significant effect than other searching methods because of the limited ratio it has. When the priority is low in the selected genes exchanged, the possibility of the big chance gets smaller. Therefore, we use the $6 \%$ mutation ratio in our study in order not to miss 
better fitness. The mutation process is illustrated in Fig. 10. The mutation is only done in the stage with swapping similar genes that affect the same variable.

\subsection{Computational Results}

The utilization rates of manufacturing centers determined by the solution of the model, amount of flow between the products held in the warehouse and the facilities are shown in Fig. 11.

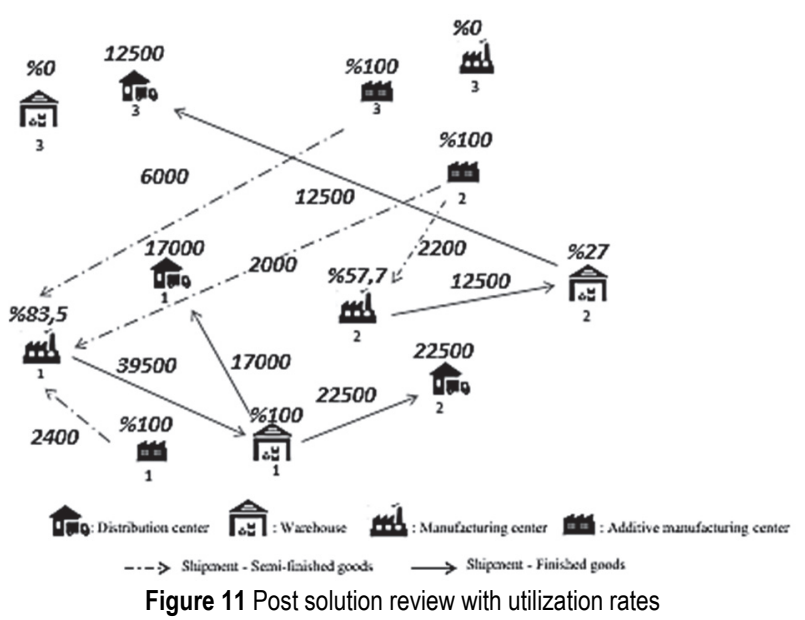

Lingo 11 and Matlab has been used for solving the problem. With SSPBA methodology, solution time has been decreased significantly.

When the results are analysed, it is observed that the investment facilities 1 and 2 are used actively, and no investment has been made to the third facility. When the warehouse preferences are examined, it is seen that although the cost of investment is higher than the others, warehouse 1 is in use because it is close to distribution centers. Due to the high preparation time and low demand for semi-finished goods, products have been assigned to additive manufacturing centers in order to minimize production costs. The semi-finished products produced were sent directly to production plants 1 and 2 for the assembly process. In addition, no semi-finished goods were sent to the warehouses, which indicates that the cost of shipping has been eliminated, the capacity is effectively used, and the semi-finished product is manufactured as needed.

\subsection{Scenario Analyses}

Scenario analyses have been done with changing some of the parameters, such as demand, production costs, and capacity. Cancellation of the semi-finished good flows between manufacturing centers and warehouses has been studied as well.

Scenario-I: Semi-finished good transportation between manufacturing centers and warehouses has been eliminated. The total cost has been decreased by $14 \%$.

Scenario-II: The size of the variables has been increased. When the problem size gets larger, ILP could not be used for the solution method any more for the model defined. So, GA is the tool for near-optimal results for bigger models, and performance comparison can be seen in Tab. 17.
Table 17 Performance comparison between ILP and GA

\begin{tabular}{|c|c|c|c|c|c|c|c|c|c|c|c|c|}
\hline \multirow[b]{2}{*}{ Size } & \multicolumn{7}{|c|}{ Variables } & \multirow[b]{2}{*}{ Lingo } & \multirow[b]{2}{*}{ Time } & \multirow[b]{2}{*}{ GA } & \multirow[b]{2}{*}{ Time } & \multirow[b]{2}{*}{ Gap } \\
\hline & $A$ & I & $\mathrm{s}$ & $\mathbf{K}$ & $\mathbf{J}$ & $\mathbf{Y}$ & $T$ & & & & & \\
\hline \multirow[b]{2}{*}{ Small } & 3 & 3 & 3 & 3 & 3 & 5 & 1 & 3405 & 00:00:01 & 3405 & 00:01:08 & $100,00 \%$ \\
\hline & \begin{tabular}{l|l} 
\\
\end{tabular} & \begin{tabular}{l|l}
3 \\
\end{tabular} & 3 & 3 & \begin{tabular}{l|l}
3 \\
\end{tabular} & 5 & & 4015,3 & 00:00:02 & 4017 & 00:04:48 & $99,96 \%$ \\
\hline \multirow[b]{2}{*}{ Medium } & 3 & 3 & 3 & 3 & 20 & 35 & & $\mathrm{x}$ & $\mathrm{x}$ & 28263 & 00:06:10 & $\mathrm{x}$ \\
\hline & 10 & \begin{tabular}{l|l}
3 \\
\end{tabular} & 3 & 3 & 80 & 100 & & $\mathrm{x}$ & $\mathrm{x}$ & 105547 & 00:15:18 & $\mathrm{x}$ \\
\hline Large & 10 & 3 & 3 & 3 & 100 & 120 & 6 & $\mathrm{x}$ & $\mathrm{x}$ & 103280 & 00:23:18 & $\mathrm{x}$ \\
\hline
\end{tabular}

\section{CONCLUSIONS}

In this study, it is aimed to design a spare part distribution system in the automotive sector. It has been shown that by eliminating some transport activities by electronic data transfer, time and cost can be saved. It is emphasized that the positive effects of this way on the distribution of automotive services in which distributed end-to-end distribution activities are frequently experienced and distributed in the form of dispersed activities on efficiency and customer satisfaction. Addition to concept, SSPBA methodology has been developed to reduce solution time in GA approach differently from other studies as a contribution to literature.

Additive manufacturing facilities used with 100\% efficiency shows that these facilities become a bottleneck, and the investment in these facilities will be in return. Especially in the production of products with low demand, the need for requirements such as mold, stock, process information makes the use of 3D printers attractive. 3D printers can be integrated into production facilities and investment decisions can be made in accordance with production volume. 3D printers create a room for low cost manufacturing, R\&D and that will enable different options in the supply chain. The technical drawings, suppliers, customer databases and systems in which the data are processed dynamically will be essential for the sustainability.

Future studies on project management may also be evaluated, in which the parameters and cost items are diversified. From a sectoral perspective, these solutions are considered to be of great value.

\section{REFERENCES}

[1] See http://www.oica.net/category/production-statistics/ 2017-statistics

[2] See https://www.statista.com/statistics/281134/number-ofvehicles-in-use-worldwide

[3] Cohen, M. \& Agrawal, N. (2006). Winning in the Aftermarket. Harvard Business Review, 84, 129-138.

[4] See http://gitacloud.com/blog/2016/10/11/automotive-spare -parts-business-business-challenges-and-supply-chainexcellence-strategies

[5] Rudolph, J. \& Emmelmann, C. (2017). The 50th CIRP Conference on Manufacturing Systems A Cloud-based Platform for Automated Order Processing in Additive Manufacturing. Procedia CIRP, 63, 412-417. https://doi.org/10.1016/j.procir.2017.03.087

[6] Chekurov, S. \& Salmi, M. (2017). Additive Manufacturing in Offsite Repair of Consumer Electronics. Physics Procedia, 89, 23-30. https://doi.org/10.1016/j.phpro.2017.08.009

[7] Mandic, M., Galeta, T., Raos, P., \& Jugovic, V. (2016). Dimensional accuracy of camera casing models 3D printed on Mcor IRIS: A case study. Advances in Production Engineering \& Management, 11(4), 324-332. http://dx.doi.org/10.14743/apem2016.4.230 
[8] Silva, J. \& Rezende, R. (2013). Additive Manufacturing and its future impact in logistics. IFAC, 46(24). https://doi.org/10.3182/20130911-3-BR-3021.00126

[9] Holmström, J., Partanen, J., Tuomi, J., \& Walter, M. (2010). Rapid manufacturing in the spare parts supply chain: Alternative approaches to capacity deployment. Journal of Manufacturing Technology Management, 21(6), 687-697. https://doi.org/10.1108/17410381011063996

[10] Altiparmak, F., et al. (2009). A steady-state genetic algorithm for multi-product supply chain network design. Computers and Industrial Engineering, 56(2), 521-537. https://doi.org/10.1016/j.cie.2007.05.012

[11] Afrouzy, Z., et al. (2016). A genetic algorithm for supply chain configuration with new product development. Computers and Industrial Engineering, 101, 440-454. https://doi.org/10.1016/j.cie.2016.09.008

[12] Shoja, A., et al. (2019). Adaptive meta-heuristic algorithms for flexible supply chain network design problem with different delivery modes. Computers and Industrial Engineering, 138, 106107. https://doi.org/10.1016/j.cie.2019.106107

[13] Ecek, N. \& Çinar, E. (2017). Otomotiv Sektörünün Dünyadaki ve Türkiye'deki Değişimi. Özet Otomotiv Sektörünün Gelişimi ve Durumu, 7(November), 685-695.

[14] Michalewicz, Z., Vignaux, G. A., \& Hobbs, M. (1991). A non-standard genetic algorithm for the nonlinear transportation problem. ORSA Journal on Computing, 3, 307-316. https://doi.org/10.1287/ijoc.3.4.307

[15] Altiparmak, F., et al. (2006). A genetic algorithm approach for multi-objective optimization of supply chain networks. Computers and Industrial Engineering, 51, 196-215. https://doi.org/10.1016/j.cie.2006.07.011

\section{Contact information:}

Umut Rifat TUZKAYA, PhD, Professor

Industrial Engineering Department, Yıldız Technical University,

YTÜ Endüstri Mühendisliği Bölümü A-609,

Barbaros Bulvarı - 34349, Beşiktaş/lstanbul

E-mail: tuzkaya@yildiz.edu.tr

Sinan ŞAHIN, MSc, PhD programme

(Corresponding author)

Graduate School of Natural and Applied Sciences, Yıldız Technical University,

YTÜ Endüstri Mühendisliği Bölümü,

Barbaros Bulvarı - 34349, Beşiktaş/lstanbul

E-mail: sinansahin@post.com 